\title{
Updated Epidemiology COVID-19 in Gansu Province, China
}

\author{
Jingchun Fan ${ }^{1,2}$, Brett D Hambly ${ }^{1,3}$ and Shisan Bao ${ }^{1,3 *}$ \\ ${ }^{1}$ School of Public Health, Gansu University of Chinese Medicine, China \\ ${ }^{2}$ Center for Evidence-based Medicine, Gansu University of Chinese Medicine, China \\ ${ }^{3}$ Discipline of Pathology, The School of Medical Sciences, Faculty of Medicine and Health, The University of Sydney, Australia
}

Submission: April 20, 2020; Published: May 11, 2020

*Corresponding author: Shisan Bao, Discipline of Pathology, The School of Medical Sciences, The University of Sydney, NSW 2006, Australia

\begin{abstract}
The outbreak of COVID-19 became a pandemic around the world with huge morbidity and high mortality. Gansu Province is in a remote region in northwest China with a population of 26.4 million within its area of $425,900 \mathrm{~km}^{2}$, but the population density in the CBD of the capital city, Lanzhou, is even bigger than Beijing. The geographic importance of Gansu is due to being a key transportation hub connecting to five provinces in northwest China. Fortunately, only a total of 92 indigenous COVID-19 cases are confirmed in Gansu till now, including both primary and secondary patients, which is considered to be a consequence of the strict screening approach applied in Gansu during the period of outbreak. Consequently, the emergency response measures to COVID-19 were able to be decreased from level 1 (top) to level III (low). Furthermore, there are some reverse transmission cases from other countries during March 2019. There were 37 confirmed COVID-19 infections among 311 evacuated Chinese from Iran. Gansu authorities undertook full preparation in advance, involving high level, streamlined cooperation between the transportation department, quarantine department and medical resource department. In addition to these organized returnees from Iran, 10 COVID-19 patients were confirmed amongst independent travellers from abroad, who unfortunately were able to scatter within the community, causing a significant potential risk to spread COVID-19. These data highlight the need for an exceptionally high level of vigilance and for a preemptive response, to prevent reverse infection occurring within a community where the pandemic had been successfully controlled.
\end{abstract}

Keywords: COVID-19 outbreak; SARS-CoV-2; Asymptomatic cases; Imported cases

Abbreviations: COVID-19: Coronavirus Disease 2019; SARS-CoV-2: Severe Acute Respiratory Syndrome Coronavirus 2; QR code: Quick Response Code

\section{Introduction}

SARS-CoV-2 is a new virus responsible for the outbreak of COVID-19, which has been transmitted to almost every country around the world within two months since it was first identified in Wuhan, Hubei Province, China in December of 2019 [1]. Globally, 210 countries and territories have reported a total of 2,259,001 confirmed cases of COVID-19, and a death toll of 154,390 deaths up till 18 April 2020 [2]. Additional confirmed cases are being identified internationally at a rapidly growing rate.

Although Gansu Province is located in a rather remote region in China, geographically Gansu is a key transportation hub connecting to five provinces in northwest China. Furthermore, Gansu has complex terrain with mountains, plateaus, plains, and the Gobi desert [3]. The population of Gansu is 26.4 million, residing within its area of $425,900 \mathrm{~km}^{2}$ [4]. Interestingly, the population density is relatively low in Gansu, however, the population density in the Central Business District of Lanzhou (Capital of Gansu) is $050,000 / \mathrm{km}^{2}$, which is more than many of the highly dense cities in China, such as Beijing and Shanghai [5], due to its location within a narrow river valley. Gansu is about $1400 \mathrm{~km}$ from Wuhan, the pandemic epicentre within China, consequently it has been relatively less affected by COVID-19. However, the complex geographical factors mentioned above have the potential to increase the risk of COVID-19 spread and the difficulty of prevention and control.

\section{Discussion}

Since the first case of COVID-19 diagnosed on 23 January 2020 in Gansu Province, there have been in total 92 indigenous 
confirmed cases in Gansu till now (18 April 2020) [6]. During the early phase of the epidemic the patients were mainly primary patients, who had travelled from COVID-19 epidemic areas, but in the second phase the patients were mainly secondary patients who had never left Gansu Province but were infected by the primary patients [7]. The relatively small number of COVID-19 cases in Gansu is probably due to the strict screening approach during the period of the outbreak, which has largely come under controlled [8], mainly as a consequence of the implementation of a series of measures, including mandatory wearing of facemasks, and extremely strict limitations on outdoor and group activities, particularly mandating almost no public and/or private social gatherings [9]. As a consequence of this largely successful containment strategy, the emergency response measures to COVID-19 were decreased from level 1 (top) to level III (low) on $2^{\text {nd }}$ March 2020, because there had been no new confirmed COVID-19 case for 16 consecutive days [10]. These data provide a clear example of the critical impact of incoming travelers, mostly asymptomatic at the time of travel, initiating the local epidemic within a discrete and geographically defined population, and the effectiveness of a robust containment strategy when rigorously applied within that population.

As the epidemic progressively came under controlled in China, alarmingly rapid spread of the virus occurred within Italy and Iran [11]. In order to seek shelter from the risk of exposure to the SARSCoV2 virus and to ensure access to adequate medical resources, overseas Chinese sought to return to China from these and similar high-risk regions. As the designated province for receiving evacuees by the Chinese authority, 311 evacuated Chinese citizens from Iran were sent to Lanzhou, using two charter planes [12], and shortly after arrival 37 evacuees were confirmed to have a COVID-19 infection [13]. Local Gansu authorities undertook full preparation in advance for the evacuation, involving high level, streamlined cooperation between the transportation department, quarantine department and medical resource department, to make sure these people would not contact any others and would be effectively quarantined within designated hotels, to isolate for 14 days. However, in addition to these organized returnees from Iran, 10 COVID-19 patients were confirmed amongst independent travelers from abroad, including oversea students, general travelers, and business workers [14]. Unfortunately, many of these infected returnees were able to scatter within the community without being quarantined, which caused a significant potential risk to spread COVID-19. The failure to quarantine many of these returnees was largely due to their early return, when the epidemic was not considered to be serious outside of China, or in some cases, they were exhibited an asymptomatic infection [15]. These data highlight the need for an exceptionally high level of vigilance and the need for a pre-emptive response, to prevent reverse infection occurring within a community where the pandemic had been successfully controlled, from returnees from other international locations, where the extent of infection at those distant sites had not yet been fully realized.
After many weeks of the lockdown all over China, especially in Hubei Province, the Chinese government has launched a health QR code system on the smartphone to keep the virus from further spreading, as China eases the lockdown allowing residents to restart normal activities, e.g. working and studying [16]. The green code means individuals are ok to participate these activities without risk of infection. However, it has been noticed that one asymptomatic person with a green code from Hubei Province was subsequently confirmed as a COVID-19-infected patient in a hospital in Lanzhou on 28 March 2020 [17]. Furthermore, other asymptomatic cases in other regions are constantly being reported. A recent report has shown that there is no difference in the secondary infection rate within the population following exposure to confirmed cases exhibiting symptoms compared to asymptomatic cases [18]. Consequently, the Chinese government has urged responsible authorities to focus on detection of asymptomatic cases and authorities have begun to report asymptomatic cases from $1^{\text {st }}$ April 2020 [19]. In an attempt to address the issue of asymptomatic carriers, Australia has proposed a system of sentinel testing of people, where random, but potentially risky, individuals will be tested irrespective of having any symptoms. The aims of this measure will be, firstly, to attempt to gauge the extent of asymptomatic carriers, and secondly, to attempt to detect infection clusters before any symptomatic individuals develop symptoms, to then guide targeted testing amongst the contacts of that sentinel individual [20]. A good example of this approach from Australia would be to test several sentinel staff members from every aged care facility, irrespective of symptoms. Clearly, if a sentinel staff member is determined to be an asymptomatic carrier, authorities would then target testing and robust quarantine within the affected aged care facility.

The most important task for the Chinese authorities is to identify these potential COVID-19 risk populations, including local residents and/or overseas returnees, using a more sensitive diagnostic approach and probably also to offer some more flexible quarantine locations to deal with people who have been determined to be within an infection cluster. These data highlight the substantial difficulties associated with the detection of, and the disastrous potential for spread from, asymptomatic carriers.

\section{Conclusion}

In conclusion, COVID-19 is has been well controlled within the defined population of Gansu Province of China, which represents an interesting case study of epidemic spread and the effectiveness of a range of responses to that spread. However, continuing robust vigilance, combined with aggressive control measures remains essential, particularly in relation to documented cases of reverse transmission from returning overseas Chinese citizens and other travelers, and/or asymptomatic SARS-CoV-2 virus carriers, who should be taken care of rigorously to ensure the final complete success of pandemic containment to preventing second outbreak of COVID-19. 


\section{Acknowledgement}

This study was funded by Talent Introduction Program of Gansu University of Chinese Medicine (no. 2016YJRC-01), Special project on COVID-19 Emergency Prevention and Treatment of Gansu University of Chinese Medicine (2020XGZX-10) and University Innovation Capacity Improvement Project in Gansu Province, Department of Education of Gansu Province, China (J.F.) and SJTU grants 2019, The University of Sydney (to S.B.).

\section{References}

1. Zhu N, Zhang D, Wang W, Li X, Yang B, et al. (2020) A Novel Coronavirus from Patients with Pneumonia in China, 2019. N Engl J Med 382(8): 727-733.

2. Worldometer. Countries where COVID-19 has spread.

3. Baike Baidu. Gansu Province.

4. Gansu. China. Introduction for Gansu Province.

5. The World's Population. Population density-Lanzhou.

6. Health Commission of Gansu Province. There were no new confirmed COVID-19 cases in Gansu with a total of 91 cases.

7. Fan J, Liu X, Pan W, Douglas MW, Bao S (2020) Epidemiology of 2019 Novel Coronavirus Disease-19 in Gansu Province, China, 2020. Emerg Infect Dis 26(6).

8. National Health Commission of the People's Republic of China. Situation report-update on COVID-19 up to 19 March 2020.
9. National Health Commission of the People's Republic of China. Prevention and control plan of COVID-19 (The fifth edition).

10. Health Commission of Gansu Province. Change of risk of new crown pneumonia in sub-counties of gansu province.

11. World Health Organization. Coronavirus disease 2019 (COVID-19) Situation Report - 41 .

12. People's Government of Gansu Province. A second chartered plane carrying 163 Chinese nationals from Iran has arrived in Lanzhou.

13. Health Commission of Gansu Province. The returnees from Iran have been completed quarantined and cured in Gansu Province.

14. Health Commission of Gansu Province. A new confirmed COVID-19 case was imported from abroad on April 5 in Gansu Province.

15. Health Commission of Gansu Province. Two new confirmed COVID-19 cases were imported from abroad on March 13 in Gansu Province.

16. Chinadaily. Health QR code helps curb the spread of COVID-19.

17. Health Commission of Gansu Province. One new confirmed case of COVID-19 imported from Hubei Province was confirmed in Gansu Province.

18. Chen Y, Wang A, Yi B, Ding K, Wang H, et al. (2020) The epidemiological characteristics of infection in close contacts of COVID-19 in Ningbo city. Chin J Epidemiol.

19. Reuters Editorial. China starts to report asymptomatic coronavirus cases.

20. Mcilroy T, Margo J. Australia adopts 'sentinel testing' regime to beat coronavirus.

\section{Your next submission with Juniper Publishers} will reach you the below assets

- Quality Editorial service

- Swift Peer Review

- Reprints availability

- E-prints Service

- Manuscript Podcast for convenient understanding

- Global attainment for your research

- Manuscript accessibility in different formats

( Pdf, E-pub, Full Text, Audio)

- Unceasing customer service

Track the below URL for one-step submission

https://juniperpublishers.com/online-submission.php 